\title{
Essay Reviews
}

JAMES A. GILLESPIE, The price of health: Australian governments and medical politics 1910-1960, Studies in Australian History, Cambridge University Press, 1991, pp. xvii, 358, $£ 40.00, \$ 59.50$ (0-521-38183-5).

ROY MacLEOD and DONALD DENOON, Health and healing in tropical Australia and Papua New Guinea, Townsville, James Cook University of North Queensland, 1991, pp. viii, $214, A \$ 16.00$ (within Australia plus postage), A\$25.00 (outside Australia incl. postage) (0-86443-490-5).

LYNDA BRYDER (ed.), A healthy country: essays on the social history of medicine in New Zealand, New Zealand, Bridget Williams Books, 1991, pp. 252, NZ\$29.95 (0-908912-10-2).

These three books present some of the best recent research in the burgeoning medical history field in Australia and New Zealand.

James Gillespie's monograph is the most important of the three. He provides a thorough, considered and censorious account of five decades of the enduring struggle between Australian federal and state governments and medical faction leaders over the aims of health policies, modes of supplying medical services, and the underwriting of payments to doctors. Much of Gillespie's story will appear familiar to readers in other parts of the British Commonwealth and the United States. But federal intricacies and the frequency of Labor Party administrations give his narrative a peculiarly Australian twist.

Throughout the period Labor politicians were much readier than their conservative opponents to back national hygienists in the public health bureaucracies. The hygienists wanted national efficiency and Australia for the white race. The Labor activists wanted that too, but they also yearned to institute equitable access to medical services. Both groups wanted to discipline a medical profession they regarded as grasping and careless of the national interest. Activists and hygienists often joined forces to seek legislation to tie preventive measures such as mass immunization programmes and tuberculosis surveys to universal access to private wards at public hospitals, accompanied by governmental controls on doctors' fees. Their attempts mostly failed.

Earlier writers have characterized these defeats as episodes in a simple war between good, united Labor reformers and bad, united doctors. Gillespie's analysis, the first to be grounded on a detailed examination of the evidence, is more subtle and persuasive. He shows the reformers to have been indecisive and the medical profession to have been deeply divided. The reformers could not develop a policy that might achieve their aims, yet control costs. Their rhetoric was never matched by their timid legislative forays, however much the medical spokesmen depicted them as heralding Bolshevist tyranny. General practitioners in one-man practices in working-class suburbs and struggling country towns, with large bad-debt rates, took a different view. They believed that fees guaranteed from public taxation and access to pay beds in public hospitals would lift their incomes, raise their standing and liberate them from the shackles of friendly society and industrial lodge contracts. Some of them even said that they would happily make the easy transition to a government salaried service, especially if it promised loadings for specialized skills and group practice. These half-hopeful, half-resentful leanings troubled the profession's leaders in the Australian state branches of the British Medical Association. The BMA leaders were predominantly high-flying city surgeons and honorary physicians with practices in the wealthy suburbs, with large incomes and egos to protect. They were determined to defend untrammelled fee for service, untrammelled use of public hospital wards, with means testing for uninteresting cases. The rank and file had little impact on their policy-making: many were sufficiently estranged to ignore BMA council elections and pronouncements. This left councillors free to promote, on behalf of all doctors as they claimed, the ideal of professional autonomy. They succeeded most of the time, despite the public's wishes as expressed in opinion polls, in mobilizing enough support among conservative 


\section{Essay Reviews}

voters to isolate despised "Canberra bureaucrats" and to thwart the politicians' poorly devised, modest initiatives on national health insurance, pharmaceutical benefits, and controls on fees.

There are many ironies in Gillespie's survey. In the 1930s and 1940s the lodge system at least guaranteed payments to about one-third of all practitioners from a working-class clientele with incomes at the edge of marginality to the BMA's recommended fee schedules, yet those practitioners fought tenaciously and successfully to destroy that system. The national hygienists, who had extended state control of medical services through central funding and administrative rule over tuberculosis sanatoria and clinics for venereal diseases and maternal and infant welfare, none the less blocked proposals for illness and maternity benefits schemes because these threatened medical dominance of prevention and rehabilitation. Thereby they destroyed machinery which potentially they could have used to further their vision of a fit, procreative Australian nation and preserve their powerbase.

The BMA finally triumphed as the unchallenged arbiter of medical policy in the 1950s, when a conservative federal government caved in to them. The medically qualified minister for health, Sir Earle Page, lifted controls on fees and pharmaceutical benefits and guaranteed fees with public money. Successive governments of all persuasions have since struggled with Page's legacy. Recently, the ageing of the population and the huge increase in costs associated with new medical technology have made the economic problems of health more acute than ever, and still politically insoluble. Health policy continues to be a jumble of compromises and fudged agreements, particularly in the hard-pressed hospital system. Politically unpopular areas such as mental illness and chronic disability remain the underfunded, disesteemed services they were at the outset of Gillespie's inquiry. The Australian medical system as the product of the impolicies described in Gillespie's book largely functions, like many other systems in the world, beyond the control of the parliaments, the courts and the taxpayers. And it seems, as it did in Gillespie's period, that the bulk of the people are content to have it that way.

The national hygienists also figure largely in the essays in Health and healing in tropical Australia and Papua New Guinea. The Australians, newly federated in 1901, were resolved to avoid the vicious economic and social outcomes of the exploitation of indentured Asian labourers in East Africa and, closer to home, the Straits Settlements, Fiji and Queensland itself. The hygienists and their political masters hoped, against late nineteenth-century beliefs, that Europeans could live and work in tropical Australia and Papua without degenerating morally and physically. In 1910 the federal government duly established a medical research institute in Townsville in Queensland to investigate the question; and then duly underfunded it.

The question, as Donald Denoon and Lorraine Harloe show in their compelling essays, was soon redefined to protecting white men, their wives and children from contracting "tropical" diseases from Aborigines, Melanesian indentured labourers, and Papuans, who comprised the local reservoirs of infections. Hence the institute, against the intentions of its distinguished first director, Anton Breinl, came to concentrate on malaria, yaws, hookworm, leprosy and sexually transmitted diseases. The basic health problems of all the peoples in the tropical regions, poor diet, insect vector control of malaria and dengue fever, and the protection of water supplies, were generally ignored. The illnesses which killed blacks and whites alike, dysentery and diet-related debility, alcoholism, and tuberculosis were not peculiar to the tropical regions; indeed, the latter two were introduced by the Europeans.

Much of the research reported in these essays emanates from the lively history department at James Cook University in Townsville. All the papers are instructive and will interest students of health in other tropical areas. There are resonant studies of the extremist social hygienist, Raphael Cilento, later to be influential in UNRAA, the Rockefeller Foundation and its hookworm campaign, which was an expensive irrelevance intended to improve the natives' attitude to work by making them more regular in their sanitary habits, and a memorable paper by Clive Moore on alcoholism and Melanesian labourers in Queensland. Peter Bell's account of European gold miners' bad diet and readiness to pollute their water supply, as compared with their Chinese competitors, is also a vivid illustration of how problems can be redefined to save expense and inconvenient regulation. 
The New Zealand essays are less focused and assured than those in the MacLeod-Denoon collection. They are centred on the development of the health professions, hospitals, public health policies and womens' health. There is, unfortunately, no introductory overview of New Zealand as "a healthy country" which might set the various contributions in context. The strongest papers are those by Derek Dow and Linda Bryder. Dr Dow analyses the impact on the charity hospitals of antisepsis and the new procedures and facilities it entailed. One major change was the incursion of middle-class patients to pay-bed wards attracted by the new curative possibilities. Their arrival coincided with the hospital boards' needs to raise extra money for the additional nurses and capital works, not least separate wards for middle-class patients. The old charity-based hospital system was doomed. This complicated process in New Zealand matches developments in the United Kingdom and elsewhere, but Dr Dow's account is a notably clear case study.

Dr Bryder's chapter on tuberculosis is authoritative and wide-ranging. Her discussion of sanatoria is particularly informative. But she has been constrained for space: occasionally she mentions issues, such as the Maori interest in 1938 in BCG vaccination and medical opposition to its introduction, without providing the necessary detail or explaining the outcome.

Other essays in the volume are under-researched and a couple belong to that wasteful class which list problems for research with no indication that any work is being done. Pertinent issues are casually raised and casually dropped. The author of the essay on the school medical service notes that parents were suspicious of doctors but does not tell us why and in what circumstances. More importantly, given the title of the collection, we are not told about the general condition of the children's health over time, by region, or by race. The paper on women's health provides better information on male ill-health than on the health of females and is generally muddled. The author says that admission rates for mental hospitals were higher for males than for females, echoing the differential rates for general hospitals. This disparity could shed much light on "a healthy country", but the essay has been narrowly conceived and the opportunity missed.

F. B. Smith, Australian National University

CHARLES E. ROSENBERG and JANET GOLDEN, Framing disease: studies in cultural history, Health and Medicine in American Society series, Brunswick, N.J., Rutgers University Press, 1992, pp. xxvi, 326, $\$ 48.00$ (hardback, 0-8135-1756-7), $\$ 16.00$ (paperback , 0-81351757-5).

As birds to ornithologists, so are diseases to doctors-independent entities, out there waiting to be discovered, described and counted. Some are extinct, a few are new, but the majority have always existed. Ornithologists record and classify birds into families, genera and species, and it is only in this remote sense that one could think of birds as social constructions rather than real entities. In much the same way, doctors recognize, classify, and often rearrange disease nomenclature in the light of growing knowledge. But doctors do not invent diseases; diseases are something you "catch", like 'flu.

This simple view has come under sustained historical attack since the concept of diseases as social constructions (and the related concept of social control) came into vogue. It was a useful notion for such disorders as onanism, nymphomania, neurasthenia, hysteria, and homosexuality, in which "a biopathological mechanism is either unproven or unprovable". As Rosenberg points out in his splendid introduction, the social-constructionist argument has provided new insights for a handful of "culturally-resonant diagnoses", but its usefulness as a concept is limited. Rosenberg prefers "the less problematically charged metaphor 'frame' rather than 'construct' to describe the fashioning of explanatory and classificatory schemes of particular diseases" (p. xv). "Fashioning" and "framing" are key words, and one of Rosenberg's key sentences is: "In some ways disease does not exist until we have agreed that it does, by naming it, and responding to it" (p. xiii). 